\title{
DO CORPO-TERRITÓRIO AO TERRITÓRIO-CORPO (DA TERRA): CONTRIBUIÇÕES DECOLONIAIS*
}

\author{
Rogério Haesbaert* \\ Universidade Federal Fluminense
}

Resumo: Este artigo aborda a questão do território numa perspectiva latino-americana, analisando as principais contribuições a este debate a partir do pensamento decolonial, especialmente a relação entre corpo e território, tanto no sentido do corpo como território quanto do território/terra como corpo, especialmente na ótica dos povos originários e da visão feminista.

Palavras chave: Corpo-território, território-corpo-terra, pensamento decolonial

\section{FROM BODY-TERRITORY TO TERRITORY BODY OF THE EARTH: DECOLONIAL}

Abstract:This article addresses the issue of territory from a Latin American perspective, analyzing the main contributions to this debate from the perspective of decolonial thinking, especially the relationship between body and territory, both in the sense of the body as territory and of the territory / earth as body, especially from the perspective of indigenous peoples and the feminist view. Keywords: Body-territory, body-earth-territory, decolonial thinking.

\section{DEL CUERPO-TERRITORIO AL TERRITORIO-CUERPO (DE LA TIERRA): CONTRIBUCIONES DECOLONIALES}

Resumen:Este artículo aborda el tema del territorio desde una perspectiva latinoamericana, analizando las principales contribuciones a este debate desde la aproximación del pensamiento decolonial, especialmente a partir de la relación entre el cuerpo y el territorio, tanto en el sentido del cuerpo como territorio como del territorio / tierra como cuerpo, especialmente desde la perspectiva de los pueblos indígenas y la visión feminista.

Palabras-Ilave: Cuerpo-territorio, territorio-cuerpo-tierra, pensamiento decolonial. 
la invitación que deja la propuesta cuerpo-territorio es mirar a los cuerpos como territorios vivos e históricos que aluden a una interpretación cosmogónica y política donde en él habitan nuestras heridas, memorias, saberes, deseos, sueños individuales y comunes y a su vez, invita a mirar a los territorios como cuerpos sociales que están integrados a la red de la vida y por tanto, nuestra relación hacia con ellos debe ser concebida como 'acontecimiento ético' entendido como una irrupción frente a lo 'otro'... (Cruz Hernández, 2017:43)

Uma das especificidades da leitura que podemos denominar latino-americana sobre o território está ligada ao fato de que ela parte da esfera do vivido, das práticas ou, como enfatizava Milton Santos, do "uso" do território - mas um uso que se estende bem além do simples valor de uso, compreendendo também um expressivo valor simbólico. Ao contrário de muitas geografias de matriz eurocêntrica, especialmente a anglo-saxônica, que prioriza as propriedades jurídico-políticas do território a partir da ação dos grupos hegemônicos (o território como "tecnologia de poder" [ELDEN, 2013]), na América Latina o território é lido frequentemente no diálogo com os movimentos sociais, suas identidades e seu uso como instrumento de luta e de transformação social. É o que pretendo abordar neste trabalho, tomando como referência o conceito de corpo-território, num jogo com o que proponho chamar "território-corpo".

A conceituação de território em nosso contexto vai muito além da clássica associação à escala e/ou à lógica estatal e se expande, transitando por diversas escalas, mas com um eixo na questão da defesa da própria vida, da existência ou de uma ontologia terrena/territorial, vinculada à herança de um modelo capitalista extrativista moderno-colonial de devastação e genocídio que, até hoje, coloca em xeque a existência dos grupos subalternos, especialmente os povos originários. Desdobram-se assim desde os territórios do/no corpo, íntimo (a começar pelo ventre materno), até o que podemos denominar territórios-mundo, a Terra como pluriverso cultural-natural ou conjunto de mundos - e, consequentemente, de territorialidades - aos quais estamos inexoravelmente atrelados. Tudo isso se desdobra hoje dentro daquilo que se designa como pensamento decolonial ${ }^{2}$, uma busca por pensar nosso espaço e, de alguma forma, o próprio mundo, considerando as bases espaço-temporais - a geohistória, enfim - em que estamos situados.

Um dos traços fundamentais do pensamento

${ }^{2}$ Não irei me deter aqui no debate específico do pensamento decolonial tendo em vista seu desdobramento em outro trabalho, de maior fôlego, em fase de redação (livro "Território e Decolonialidade"), e do qual este artigo, ampliado, constituic um capítulo. De qualquer forma, a questão será desdobrada, ainda que de forma indireta, ao longo do texto. Este trabalho encontra-se vinculado ao projeto

"Território como categoria da prática social numa perspectiva latino-americana", com bolsa de pesquisa do CNPq decolonial, segundo Quijano (1992, 2010), é a "colonialidade do poder", marcada por profunda herança escravista e patriarcal onde proliferam até hoje violências de classe, de raça e de gênero. Outro traço dessa episteme que nos interessa muito de perto, aqui, é dar voz aos invisibilizados, aos grupos subalternos e suas formas de saber. Daí tratarmos o território, nessa ótica, como territórios de r-existência (retomando expressão difundida por Carlos Walter Porto-Gonçalves ${ }^{3}$ ).

Podemos sintetizar as principais contribuições do debate sobre território numa perspectiva latinoamericana através de três abordagens:

a) A abordagem que, em intenso diálogo com referências europeias (especialmente anglo-saxônicas, mas também francesas) e norte-americanas, propõe o território como o conceito geográfico mais pertinente para analisar as relações espaço-poder, especialmente entre os grupos subalternos, ampliando a concepção de poder através de sua dimensão simbólica (construção identitária), o que representa uma clara imersão na decolonialidade do poder, sobretudo a partir de sua face étnico-cultural e de gênero, contra ou anti-hegemônica.

b) A abordagem que, principalmente a partir de uma perspectiva de gênero, enfatiza o território relacionado à escala primordial do corpo, o "corpoterritório", proveniente principalmente de proposições de pesquisadoras feministas (ou ecofeministas) e do movimento indígena, que atentaram para o poder da corporeidade ao mesmo tempo como objeto de exercício do poder e como sujeito (corporificado) de resistência.

c) A abordagem que amplia de tal forma a concepção de território que faz dele praticamente sinônimo de espaço de vida - embora já sugerido (mas pouco desenvolvido) por alguns geógrafos, trata-se de uma proposta oriunda de trabalhos como o do antropólogo Arturo Escobar com comunidades afrodescendentes.

Como a primeira dessas linhas de interpretação de certo modo já foi abordada em trabalhos anteriores e a terceira exigirá um espaço maior que o proporcionado por este artigo, irei me deter aqui à segunda dessas perspectivas, em especial a relação entre território e corpo/gênero e território e "T/terra", as quais proponho relacionar através das designações corpo-território e território-corpo (da terra).

${ }^{3}$ Para o autor, "dizer colonialidade é dizer, também, que há outras matrizes de racionalidade subalternizadas resistindo, $r$-existindo (...). Aqui, mais que resistência, que significa retomar uma ação anterior e, assim, é sempre uma ação reflexa, o que temos é r-existência, isto é, uma forma de existir, uma determinada matriz de racionalidade que atua nas circunstâncias, inclusive re-atua a partir de um topoi, enfim, de um lugar próprio, tanto geográfico como epistêmico. Na verdade, atua entre duas lógicas". (Porto-Gonçalves, 2013[2008]:169) Especificamente sobre resistência e decolonialidade numa perspectiva geográfica, ver o balanço feito por Pereira (2017). 
Corpo-território: território e gênero

Se ainda havia alguma dúvida sobre a relevância de um entendimento do espaço geográfico a partir da espacialidade/espacialização do corpo, por longo tempo subestimada na Geografia - e também nas Ciências Sociais em seu conjunto, ela se dissipou completamente nas últimas décadas. Como veremos, no âmbito latino-americano isso se deu especialmente através das discussões sobre gênero a partir dos movimentos feministas e, de modo mais específico, das mulheres indígenas.

Um exemplo claro da emergência da questão há 25 anos atrás foi a criação de uma revista específica denominada Body \& Space. Na Geografia, apesar de há muito mais tempo a temática do corpo ter sido objeto de tratamento (por exemplo, na Geografia e nas abordagens espaciais de base fenomenológica e/ou humanista ${ }^{4}$ ), ela só foi adquirir maior centralidade a partir dos anos 1990, quando ocorreu uma releitura, principalmente numa matriz pós-estruturalista e através de uma Geografia feminista, como aquela de Gillian Rose (1993). Essa valorização do tema ficou evidente em trabalhos como os de Steve Pile (PILE, 1996; PILE E NAST, 1998), Linda McDowell (1999) e Gill Valentine (2001)

$\mathrm{Na}$ Geografia latino-americana somente estudos mais recentes deram maior ênfase ao debate sobre o corpo - ou melhor, sobre a corporeidade, definida por Alicia Lindón como "linguagem estrutural que transpassa o corpo" (2012:703), centrada nas práticas cotidianas. Também aqui o trabalho de geógrafas feministas se destaca, como no caso de Joseli Silva. Em artigo conjunto com Marcio Ornat (SILVA E ORNAT, 2016), ela faz um percurso pelo tratamento sobre o corpo na Geografia brasileira e destaca a importância de sua leitura no interior do debate mais amplo sobre escala ${ }^{6}$. Para os autores, o corpo não pode ser tratado de modo neutro e universal, pois tem raça, sexualidade e gênero - além, é claro, de idade (faixa geracional) e classe socioeconômica?

${ }^{4}$ Embora fora da Geografia, cabe destacar o trabalho pioneiro de Otto Friedrich Bollnow (2008[1963]).

${ }^{5}$ Valentine (2001), também a partir da categoria espaço, afirma: "O corpo não apenas está no espaço, ele é espaço", como "uma superfície [de inscrição], (...) marcada e transformada pela nossa cultura", como um "ser sensitivo, a base material da nossa conexão com e da nossa experiência do mundo" e como a fronteira da psique (p. 23). Expressões como "superfície marcada pela cultura" e "fronteira" constituem alusões a traços de "territorialidade" presentes através do espaço do corpo.

${ }^{6}$ No levantamento realizado por Silva e Ornat foram identificados 28 artigos sobre o tema na Geografia brasileira, os autores ressaltando que apenas dois (Lima, 2007, e Serpa, 2013) foram publicados em revistas de maior qualificação.

${ }^{7}$ Num texto recente, relativo à pandemia de coronavírus, Lima (2020) propõe uma "geopolítica dos corpos sensíveis", correspondente "à relação formada entre espaço e poder mediada pela (inter)corporalidade. (...) trata-se de sujeitos corporificados que constituem a face vívida das realidades geopolíticas cotidianas. É como se falássemos aqui de uma geografia dos sujeitos corporificados em sua condição geopolítica".
Henri Lefebvre foi um dos autores que mais inspirou os geógrafos a partir dos anos 1970, inclusive no Brasil (embora só tenha ingressado efetivamente na Geografia anglo-saxônica depois da tradução de "A produção do espaço", em 1991) ${ }^{8}$. Ele destacou em sua obra a relevância do espaço-corpo:

\begin{abstract}
Antes de produzir efeitos no âmbito material (utensílios e objetos), antes de produzir-se (alimentando-se dessa materialidade) e de reproduzir-se (pela geração de um outro corpo), cada corpo vivo é um espaço e tem seu espaço: ele se produz no espaço e produz o espaço (LEFEBVRE, 1986[1974]:199).
\end{abstract}

Outro filósofo que, em distinta linha teórica, destacou a grande relevância do corpo no jogo das relações de poder, foi Michel Foucault. Para ele, o corpo "está diretamente mergulhado num campo político" e imbricado à utilização econômica:

\footnotetext{
.. as relações de poder têm alcance imediato sobre ele; elas o investem, o marcam, o dirigem, o supliciam, sujeitam-no a trabalhos, obrigam-no a cerimônias, exigem-Ihe sinais. Este investimento político do corpo está ligado, segundo relações complexas e reciprocas, à sua utilização econômica; é, numa boa proporção, como força de produção que o corpo é investido por relações de poder e dominação; mas em compensação sua constituição como força de trabalho só é possível se ele está preso num sistema de sujeição (...); o corpo só se torna força útil se é ao mesmo tempo corpo produtivo e corpo submisso. (FOUCAULT, 1984:28)
}

Para Foucault há assim uma "tecnologia política do corpo", às vezes muito sutil e difusa, "uma instrumentalização multiforme" que inclui inúmeras táticas e estratégias perpassando nossos corpos e agrupamentos de corpos. Mostrando a íntima implicação entre poder e saber, ele vê o "corpo político" como "conjunto dos elementos materiais e das técnicas que servem de armas, de reforço, de vias de comunicação e de pontos de apoio para as relações de poder e de saber que investem os corpos humanos e os submetem fazendo deles objetos de saber". (Foucault, 1984:30)Sua definição - e distinção - de sociedades disciplinares e sociedades biopolíticas ou de segurança implica também uma relação na forma de ver o corpo: do "homem-corpo", individualizado, ou do "corpomáquina", fundamental na consolidação da disciplina e integração no sistema produtivo, ao "corpo-espécie", o "homem-vivo" ou a "população", base da construção do biopoder, especialmente através do controle da circulação. De forma mais ampla, ele afirma:

${ }^{8}$ Para uma análise da contribuição de Lefebvre à formulação de uma "teoria geográfica do corpo", ver Simonsen (2005). 
O controle da sociedade sobre os indivíduos não é feito apenas por meio da consciência ou da ideologia, mas também no corpo e com o corpo. Para a sociedade capitalista, a biopolítica é o que mais importa, o biológico, o somático, o físico. (FOUCAULT, 1994:210)

Lefebvre e Foucault (que julgamos complementares, aqui) filiam-se a uma longa linha de filósofos que, em diferentes perspectivas, deram destaque ao espaçocorpo, de Spinoza a Nietzsche, de Heidegger a MerleauPonty. Gostaria, entretanto, de enfatizar a proposta de dois outros filósofos, mais recentes, Deleuze e Guattari, por tratarem não apenas do espaço-corpo mas daquele que se tornará uma das principais contribuições da leitura geográfica decolonial latino-americana, o território-corpo - ou, dentro de uma distinção que iremos propor, inicialmente, o corpo-território.

No livro "O mito da desterritorialização", ao mesmo tempo que fortemente inspirado em posicionamentos desses dois autores, questionei a concepção demasiado ampla de território presente na obra de Deleuze e Guattari, para quem "o território, como um dos conceitoschave da Filosofia", compreende "dimensões que vão do físico ao mental, do social ao psicológico e de escalas que vão desde um galho de árvore 'desterritorializado' [ao ser transformado em um bastão, por exemplo] até as 'reterritorializações absolutas do pensamento'". (HAESBAERT, 2004:38) Considerei também "exagerada" a expressão dos autores ao falarem de uma "territorialização" do corpo: "se for preciso, tomarei meu território em meu próprio corpo, territorializo meu corpo" (DELEUZE E GUATTARI, 1997:128). Associando aos envoltórios de animais como a tartaruga e alguns crustáceos, para eles a própria tatuagem faria do corpo um território. Entretanto, na mesma obra, relativizei essa crítica. Inspirado também em Michel Foucault, comentei sobre a centralidade dos "indivíduos-sujeitos" nos processos de reprodução e controle social, não só no que se refere à consciência, mas "também enquanto corporeidades":

Neste sentido, o controle dos corpos [enfatizando o caráter disciplinar da sociedade]- ou das "massas" [mais no caso do biopoder] - passa a ter um novo papel ainda relativamente pouco valorizado nas novas estratégias territoriais. Numa interpretação bastante ousada, é como se o território, enquanto unidade espacial funcional e expressiva, numa sociedade cada vez mais individualista, estivesse sendo comprimido na "unidade espacial mínima" que é o corpo - em outras palavras, o corpo enquanto entidade relacional, mergulhada num universo dinâmico e complexo de relações sociais, ou até mesmo algo próximo de um indivíduo-território, como indica Maffesoli (2001).
Ao se referirem à distância como uma das propriedades fundamentais do território, Deleuze e Guattari também lembram o campo da arte, em especial a dança (e mais especificamente a dança barroca, que eles identificam como "dança territorial"), onde cada pose, cada movimento, instaura uma determinada distância entre os corpos.

É interessante como a reflexão sobre o corpo como território se expandiu no campo da coreografia e da dança, a ponto, por exemplo, da bailarina e teórica de dança Julie Barnsley (2006) ter escrito um livro intitulado "El cuerpo como territorio de la rebeldia"9. Lepecki (2011), numa concepção teoricamente elaborada, a partir do caráter coconstitutivo arte-política e da "política do chão", espacialmente situada, de Paul Carter, propõe uma "coreopolítica", que "revela o entrelaçamento profundo entre movimento, corpo e lugar". (p. 51) Embora utilize mais a designação lugar do que território, é claramente também de um território (inclusive nos vínculos com a polícia) que se trata.

Enquanto conceito - ou melhor, como categoria de análise - os geógrafos ingleses, ainda nos anos 1990, reconheciam essa interação entre corpo e território (e também lugar). Para Steve Pile e Heidi Nast, por exemplo:

Pouco a pouco, os corpos se tornam relacionais, territorializados de maneiras específicas. De fato, pode-se dizer que os próprios lugares são exatamente o mesmo: eles também são constituídos por relações entre, dentro e para além deles; territorializados através de escalas, fronteiras, geografia, geopolítica (Pile e Nast, 1998:3) ${ }^{10}$

É sintomático, contudo, que sejam os indígenas e as mulheres (muitas delas também indígenas) os principais protagonistas a tratar o território como corpo, ou melhor, a problematizar a concepção de "corpo-território" na América Latina e utilizá-lo como ferramenta de luta. É importante ressaltar que na cultura nativa, indígena, em sentido mais amplo, o corpo tem um papel decisivo. Segundo Viveiros de Castro:

...os regimes ontológicos ameríndios divergem daqueles
mais difundidos no Ocidente precisamente no que
concerne às funções semióticas inversas atribuídas ao
corpo e à alma. Para os [colonizadores] espanhóis (...)

${ }^{9}$ Embora sua concepção de território seja muito ampla, fluida (território científico, conceitual, íntimo, teatral, corporal...), o título é emblemático e sugere aproximação, a partir de sua experiência venezuelana, com o corpo-território ou o territóriocorpo de feministas e indígenas latino-americanas

${ }^{10}$ Tradução livre do original em inglês: "Bit by bit, bodies become relational, territorialized in specific ways. Indeed, places themselves might be said to be exactly the same: they, too, are made-up out of relationships between, within and beyond them; territorialized through scales, borders, geography, geopolitics". 
a dimensão marcada era a alma; para os índios, era o corpo. (...) 0 etnocentrismo dos europeus consistia em duvidar [negar] que os corpos dos outros contivessem uma alma formalmente semelhante às que habitavam os seus próprios corpos; o etnocentrismo ameríndio, ao contrário, consistia em duvidar que outras almas ou espíritos fossem dotadas de um corpo materialmente semelhante aos corpos indígenas. (2015:37)

Enquanto os europeus reconheciam o "outro" corpo indígena (animais também têm corpo), marcando sua diferença pela ausência de alma, os indígenas reconheciam a "outra" alma humana (animais também têm alma), questionando sua distinção pelo fato de habitar um mesmo (ou semelhante) corpo. É como se, para os indígenas, reconhecer a diferença de alma (entre os diferentes seres) estivesse sempre ligada à diferenciação dos corpos (não poderia haver alma diferente num mesmo corpo), e a diferenciação dos corpos (humanos e não-humanos), para os europeus, estivesse ligada à presença ou ausência de alma (não podendo existir alma - prerrogativa "humana" [leiase, muitas vezes, homem branco cristão] - em corpos diferentes).

Os povos nativos desejavam saber "se o corpo daquelas 'almas' era capaz das mesmas afecções e maneiras que os seus: se era um corpo humano ou um corpo de espírito, imputrescível e proteiforme" (VIVEIROS DE CASTRO, 2013:381). Em suma, enquanto a questão colocada pelos europeus era de como poderia uma alma semelhante à sua habitar outro corpo, a dos indígenas era a de se poderia um mesmo (ou semelhante) corpo abrigar uma outra alma.

Segundo Aníbal Quijano, no caso da colonialidade do poder impregnada na formação de nossa "América Latina", a corporeidade é "o nível decisivo das relações de poder". Para esse autor:

Na exploração, é o "corpo" que é usado e consumido no trabalho e, na maior parte do mundo, na pobreza, na fome, na má nutrição, na doença. É o "corpo" o implicado no castigo, na repressão, nas torturas e nos massacres durante as lutas contra os exploradores. Pinochet é um nome do que ocorre aos explorados no seu "corpo" quando são derrotados nessas lutas. Nas relações de gênero, trata-se do "corpo". Na "raça", a referência é ao "corpo", a "cor" presume o "corpo". (2010:126)

Castro-Gómez e Grosfoguel, desdobrando o pensamento decolonial, falam mesmo de uma "corpopolítica do conhecimento", pois todo conhecimento é "in-corporado":

... aunque se tome el sistema-mundo como unidad de análisis, reconocemos también la necesidad de una corpo-política del conocimiento sin pretensión de neutralidad y objetividad. Todo conocimiento posible se encuentra in-corporado, encarnado en sujetos atravesados por contradicciones sociales, vinculados a luchas concretas, enraizados en puntos específicos de observación (...). (CASTRO-GÓMEZ e GROSFOGUEL, 2007:21, grifo dos autores)

Como lembram diversxs outrxs autorxs, a corporeidade está profundamente implicada com as questões de raça e gênero. A ênfase das mulheres ao corpo - em especial as mulheres indígenas - se deve, em grande parte, à associação, sobrevalorizada e ao mesmo tempo restritiva, que a sociedade moderno-colonial propagou entre mulher e corpo. Assim, muitas vezes, os corpos masculinos apareciam como incorpóreos e vinculados "à área da mente, hierarquizando sempre a mente [masculina] acima dos corpos [femininos]" (CRUZ HERNÁNDEZ, 2017:40). Espacialmente, é indubitável o confinamento (quando não enclausuramento) da mulher no seu próprio corpo (vide, em algumas culturas mais conservadoras, a interdição/invisibilização quase completa do corpo feminino) ou, o que é mais comum, no espaço doméstico ou "do lar".

Por outro lado, devemos reconhecer ainda a longa negligência e/ou o menosprezo em relação à multiplicidade inerente ao próprio corpo, ou seja, suas manifestações em termos de classe, gênero, raça, identidade nacional/regional, capacitação física e idade ou faixa geracional. No caso latino-americano devese destacar o amplo domínio, histórico, de uma visão patriarcal de sociedade - fortalecida pelo processo de dominação e exploração colonial mas que, sem dúvida, o antecede, impregnada no histórico cultural opressor de muitas comunidades pré-coloniais - sem ignorar que algumas delas, ao contrário, matriarcais, destacaram-se pelo papel protagônico das mulheres.

Outra marca da geografia latino-americana que tem sérias implicações em termos de desigualdade de gênero é a economia de caráter extrativo difundida de longa data por todo o continente (autores como Gudynas, 2009, e Svampa, 2019, enfatizam suas especificidades atuais através da denominação neoextrativismo). Assim, lembra Cruz Hernández (2017), espaços extrativistas são altamente masculinizados e a instalação de empresas provoca uma "patriarcalização dos territórios". 0 aumento da violência nesses espaços dominantemente masculinos é mais um fator que leva ao engajamento das mulheres, especialmente aquelas vinculadas à vivência comunitária dos povos originários, contra essas formas de exploração e patriarcalização.

É nesse contexto que surgem inúmeros movimentos 
capitaneados por mulheres, sobretudo mulheres indígenas, que proclamam a "defesa do corpo e do território". Um exemplo recente, no Brasil, foi a $1^{\text {a }}$ Marcha das Mulheres Indígenas, realizada em agosto de 2019 na capital federal, Brasília. Sua relevância se expressa pelo fato de ter reunido, pela primeira vez, 2.500 mulheres de 130 povos indígenas distintos, representando todas as cinco grandes regiões do país. No documento final que divulgaram afirmam:

\begin{abstract}
...queremos dizer ao mundo que estamos em permanente processo de luta em defesa do "Território: nosso corpo, nosso espírito".(...) Enquanto mulheres, lideranc,as e guerreiras, geradoras e protetoras da vida, iremos nos posicionar e lutar contra as questões e as violac,ões que afrontam nossos corpos, nossos espíritos, nossos territórios. Difundindo nossas sementes, nossos rituais, nossa língua, nós iremos garantir a nossa existehcia. (...) Precisamos dialogar e fortalecer a potencia das mulheres indígenas, retomando nossos valores e memórias matriarcais para podermos avanc,ar nos nossos pleitos sociais relacionados aos nossos territórios ${ }^{11}$.
\end{abstract}

Essa articulação entre corpo e território, de modo mais amplo, "coloca no centro o comunitário como forma de vida", permitindo abordar o território em múltiplas escalas, ressaltando a importância da "escala mais micro, mais íntima, que é o corpo", "primeiro território de luta". O corpo, e notadamente o corpo feminino e de outros grupos dissidentes, revela a concretude de inúmeras "outras escalas de opressões, de resistências: família, praça pública, comunidade, bairro, organização social, território indígena, etc." (CRUZ HERNÁNDEZ, 2017:43) A autora afirma que a concepção "corpo-território" é "uma epistemologia latino-americana e caribenha feita por e desde mulheres de povos originários" e inclui suas posições dentro do que denomina "novos olhares ecofeministas desde o Sul" (que inclui seu "Colectivo Miradas Críticas del Territorio desde el Feminismo", criado em 2012).

Outro autor importante neste debate é Echeverri (2004, ECHEVERRI E BOTERO, 2002), um dos pioneiros na proposição não apenas de um "corpo[como]território" mas também de um território no interior do próprio corpo. Echeverri propôs o território antes de tudo como "apetite, pulsão vital, desejo", partindo do modelo de crescimento de um ser vivo. Assim, faz um percurso escalar que tem início no ventre materno:

...o primeiro território de toda criatura é o ventre materno: um mar salino de onde a criatura obtém

${ }^{11 D}$ Documento disponível em : https://cimi.org.br/2019/08/marcha-mulheresindigenas-documento-final-lutar-pelos-nossos-territorios-lutar-pelo-nossodireito-vida/ (acessado em novembro de 2019) seu alimento e satisfaz seus desejos. Com a ruptura do nascimento, o território do bebê se torna o corpo de sua mãe e, sobretudo, seu seio de amamentar. Desde aí, esse território que foi único e autocontido deve estabelecer relações e tomar substâncias de outros "territórios" [inclusive de outras espécies] (ECHEVERRI, 2004:263, grifo do autor).

Echeverri ressalta também a imbricação entre "naturalização" e "socialização" territorial, ao lembrar a crescente necessidade de valer-se de territórios alheios, ou seja, do corpo de outros - e do corpo-terra, poderíamos dizer -, a fim de garantir sua reprodução e sobrevivência. Constrói-se assim um circuito de relações, de conflito ou complementaridade, com outros "agentes naturais ou humanos". No caso dos indígenas que partilham dessa concepção de território, eles se territorializam muito mais na forma de redes (onde o autor enfatiza os "canais" que entrelaçam os nós das redes) do que de zonas ou áreas, como predomina na ordem jurídico-estatal hegemônica.

Outra autora importanteneste debate, eque aprofunda essa leitura "corpo-internalizada" do território a partir de uma perspectiva geográfica, ou melhor, geopolítica, é Sofia Zaragocin. Apesar de se declarar investigadora na ótica de uma "geopolítica feminista decolonial", a autora não abre mão de um fértil diálogo com as referências do debate anglo-saxônico. É a partir dessa interlocução que ela desdobra um conceito como "colonialidade de colonos" (settler colonialism, no original inglês), fundamentada, entre outros, nos trabalhos de Wolfe (1999) e Veracini $(2011,2014)$. Essa colonialidade de colonos traz uma contribuição importante à medida que enfatiza a dimensão espacial das dinâmicas colonizadoras onde, além de um genocídio e/ou etnocídio das populações originárias trata-se de uma "invasão estrutural" (nos termos de Wolfe) visando a expropriação, espoliação e reapropriação do território e de extração de seus recursos.

É dentro desse verdadeiro projeto colonial de desre-territorialização que surgem e se difundem os mais diversos processos de resistência (ou de r-existência), como o que Zaragocin (2018a) analisa entre as mulheres Étera no norte-pacífico equatoriano. Diante da ameaça de extinção do grupo indígena, elas "propõem o útero como trincheira desde a qual confrontam a morte coletiva". Assim, sua luta contra diversas formas de violência cria "uma territorialidade através dos papéis e corporeidades reprodutivas", configurando o que Zaragocin, de forma provocadora, propõe denominar uma "geopolítica do útero". (2018a:1)

Cabe ressaltar que essa ousada proposição pautouse nas categorias da prática formuladas pelos povos 
originários investigados pela autora. É evidente que esse uso extraordinariamente amplo das designações território e territorialidade, ainda que ancorado em práticas efetivas, exigem uma maior precisão conceitual, a fim de alcançar um maior rigor analítico ${ }^{12}$. Ainda que se mantenha o mesmo termo, cada mudança de escala implica numa série de transformações em termos de poder decisório/autonomia e, assim, mais amplamente, de maneiras de afetar outros territórios/territorialidades ou, se quisermos, outros corpos (órgãos?) e/ou consciências transescalarmente imbricados.

Assim, temos que analisar com cuidado afırmações como a de que "o corpo gera territorialidade, mas há partes do corpo que geram territorialidades distintas", ou que o útero "é a parte do corpo onde pode haver maior autonomia e empoderamento ao decidir-se por não ter filhos ou ao interromper uma gravidez" (Zaragocin, 2018a:12, grifos nossos). De fato, não são "partes do corpo" que geram territorialidades ou que "fazem resistência" ("há partes do corpo que podem fazer resistência de maneira distinta que outras" [p. 11, grifos nossos]). É fundamental manter a "condição territorializadora" no corpo ou no órgão corporal enquanto pertencente e sob o poder decisório de uma pessoa (ou grupo, no caso de iniciativa tomada pelo conjunto de uma etnia indígena, por exemplo). Como bem expressa a autora, exemplificando partes do corpo que "podem fazer resistência de maneira distinta": "pessoas com próteses geram uma territorialidade distinta através dessa parte de seus corpos" (Zaragocin, 2018a:11, grifos nossos) ${ }^{13}$.

Quando Zaragocin, citando Cruz Hernández (2016) e Cabnal (2010), considera que "os corpos e os territórios são ontologicamente um todo" (2018a:4), fica claro que tanto o corpo ou a corporeidade, relacionalmente falando, pode ser tratada como um território ("primeiro território", ela dirá a seguir, indiretamente problematizando a ideia de "útero-território"14), como pode também ser

${ }^{12}$ Cruz Hernández (2016) reconhece que, apesar do uso que faz das concepções corpo-terra e corpo-território, elas realizam descrições que "permanecem mais no enunciado político e de luta que como categoria de análise".

${ }^{13} \mathrm{O}$ u então, "... as mulheres reivindicam esta parte do corpo [o útero] para criar uma territorialidade de resistência" Sem dúvida, quem "gera" ou produz territorialidade é a "pessoa", por intermédio de seu corpo ou de um órgão ou prótese de seu corpo - esse corpo e/ou esse órgão/prótese constituindo, é claro, parcela fundamental do processo de (re)territorialização (até porque, no caso do útero, ele é uma prerrogativa do corpo feminino - ou, para manter o mesmo rigor da autora, de mulheres e transexuais)

${ }^{14} \mathrm{Na}$ verdade, em Zaragocin, 2018, a autora não utiliza explicitamente a concepção de útero como território, mas sim de útero como "entidade geopolítica" (o que, para muitos, poderia equivaler a um sinônimo), ou "útero-territorialidade". Quanto ao corpo como primeiro território essa concepção já se encontra no trabalho de Cabnal (2010) ao reivindicar "la recuperación consciente de nuestro primer territorio cuerpo, como un acto político emancipatorio y en coherencia feminista com 'lo personal es político', 'lo que no se nombra no existe'". (p. 22) E acrescenta depois: "Las violencias históricas y opresivas existen tanto para mi primer territorio cuerpo, como también para mi territorio histórico, la tierra. En ese sentido todas las formas de violencia contra las mujeres, atentan contra esa existencia que debería ser plena". (p. 23) distinguido (mas nunca dissociado) de territórios em sentido mais amplo, correspondentes de forma explícita aos diferentes ambientes em que nossos corpos (individuais ou em grupo) encontram-se envolvidos.

Nas palavras de Cabnal (2010), essa íntima aliança corpo-território-terra se manifesta no que ela denomina "recuperación y defensa histórica de mi territorio cuerpo tierra", assumindo "la recuperación de mi cuerpo expropiado, para generarle vida, alegría vitalidad, placeres y construcción de saberes liberadores para la toma de decisiones". Essa potência se junta com a defesa do "território terra", pois não é possível conceber seu corpo de mulher "sin un espacio en la tierra que dignifique mi existencia, y promueva mi vida en plenitud" (p. 23).

\section{Território-corpo (da terra): a t/Terra como corpo}

No poema "Naturaleza de Mmá" (a terra), os índios wayuu da região entre a Venezuela e a Colômbia associam montanhas e pedras a ossos, "porque todas las rocas constituyen los huesos de la tierra", rios, fontes e lagos a "su sangre, sus lágrimas, su savia" e areia e barro a "sus carnes, sus músculos, sus vísceras". E concluem:

\footnotetext{
Su seno es cálido como la matríz. Su corazón es fuego. Pero las demás partes de su cuerpo se ocultan a nuestras vistas porque son divinas y no alcanzamos a comprenderlas. ${ }^{15}$
}

Um texto-poema como esse muitas vezes expressa de modo muito mais denso uma relação - ou condição que pretendemos compreender: neste caso, a vivêncialeitura dos povos originários da "terra-território" como corpo. 0 elo entre território e corpo inclui, de fato, diversas modalidades de (inter)relações e escalas de interpretação.

A partir do reconhecimento da relevância das mudanças implicadas na distinção desses jogos de escala ${ }^{16}$, com esse foco analítico-escalar pode-se identificar pelo menos quatro abordagens, as quais proponho denominar: "corpo-território" ou o corpo como território; território do/no (interior do) corpo (como

${ }^{15}$ Esse belo poema, gentilmente enviado por Angel Quintero Weir, é, em suas palavras, um "texto-poema de nuestro desaparecido Maestro Wayuu Ramón Paz lipuana que él tituló: Naturaleza de Mmá (la tierra)"

${ }^{16} \mathrm{~A}$ propósito da importância da análise escalar, Cruz (2017) menciona a "leitura multiescalar" como um dos desafios fundamentais do pensamento decolonial sob uma perspectiva geográfica. Ela deve ser capaz, ao mesmo tempo, "de compreender a colonialidade do poder, do saber, do ser e da natureza em termos macro e micropolíticos, tanto em termos de elementos estruturais como através das práticas e experiências cotidianas". Sem esquecer, é evidente, seu acoplamento com a "multiplicidade de temporalidades e ritmos" que envolve a "complexidade dos processos concretos". (p. 31) 
vimos para o caso do útero); território como conjunção de corpos ("população") e "território-corpo (da terra)" no caso das leituras da terra/Terra como um corpo - ou, mais simplesmente, do caráter ontológico, existencial da terra/Terra como território, prolongamento indissociável do nosso corpo, tal como transmitido pelo mestre wayuu lipuana em seu poema.

As duas primeiras abordagens foram aquelas trabalhadas no item anterior, com base nas proposições do pensamento feminista e indígena latino-americano. Enquanto o "corpo-território" vê o corpo (especialmente o corpo da mulher) no seu conjunto como nosso primeiro território, o "território do/no corpo" admite a territorialidade dos próprios órgãos que o compõem, como no enfoque de Echeverrí (2002) ao definir o ventre materno como "primeiro território" ou Zaragocin (2018a) ao conceber a condição territorial do útero.

A terceira perspectiva, embora não conheçamos referência anterior explícita à sua concepção, pode ser deduzida, dentro desse jogo múltiplo de escalas, como aquela que concebe o território ou, pelo menos, a territorialidade (enquanto condição de/para a territorialização), a partir da conjugação de corpos ou, como denominaria a biopolítica foucaultiana, da "população", especialmente em seus efeitos de "massa" (ou enquanto "corpo político da nação"). Como não se trata diretamente de uma perspectiva de matriz decolonial e/ou como categoria da prática, tendo, portanto, raízes mais analíticas sem diálogo com o uso na prática social, pelo senso comum, ela será desdobrada em um trabalho mais amplo que está em fase de finalização.

A abordagem do território-corpo da terra, terraterritório como corpo ou, simplesmente, do territóriocorpo, em seu sentido mais direto, merecerá maior atenção, aqui, especialmente por sua vinculação muito nítida com um pensamento latino-americano de matriz decolonial. Trata-se da concepção que, como que invertendo o raciocínio em torno do corpo-território, considera a própria terra (neste caso, componente indissociável do território) como corpo, ampliando em muito, metaforicamente, a concepção comumente difundida de corporeidade.

Podemos propor denominá-lo simplesmente "território-corpo", na medida em que, desde sua origem etimológica, o território está ligado ao domínio e/ou apropriação da terra, da chamada primeira natureza. Alguns autores, entretanto, preferem trabalhar não com a designação "território-corpo", que pode ser confundida ou ter uma distinção muito pouco explícita em relação a "corpo-território", mas com a tríade "terraterritório-corpo". Outros, ainda, optam por destacar a relação território-natureza (ao invés de terra) ou, então, por utilizar simplesmente a expressão "corpo-terra", enfatizando a visão da terra (na maioria das vezes sinônimo de território) como corpo. Preferimos, para efeito deste texto, utilizar o termo "território-corpo (da terra)".

A diferenciação aqui proposta entre corpo-território e território-corpo (da terra) envolve apenas uma questão de ênfase, pois se trata sempre de uma perspectiva relacional, ora privilegiando a direção que vai do corpoterritório à terra, ora da terra-território ao corpo. Por isso, esses movimentos encontram-se imbricados de forma indissociável, como veremos na própria vivência de um povo indígena como os wayuu, detalhada logo adiante. Trata-se, sobretudo, de um instrumento analítico, mas profundamente alicerçado no contexto empírico das categorias da prática dos povos originários, a fim de destacar:

a) as implicações das mudanças nos jogos de escala, como já foi comentado;

b) a indissociabilidade corpo-terra para a efetivação daquela que consideramos, ao lado do corpo-território, uma das grandes contribuições do pensamento decolinial latino-americano ao debate sobre território, a da sua leitura pelo viés ontológico, da defesa do território como espaço de vida, da existência em sentido amplo, o que implica também considerar toda a experiência de extrema violência (sobretudo contra a mulher) difundida em nosso continente. Denomino esta perspectiva, que deve, obrigatoriamente, envolver a do corpo-território, "território de r-existência".

Vários autores destacam, especialmente entre as comunidades indígenas, uma relação profunda entre os grupos sociais e o território que, em alguns casos, é visto explicitamente como uma continuidade ou uma extrapolação, em outra escala, de nossa condição corpórea, isto é, de nossa corporeidade. Assim, por exemplo, Quintero Weir (2019) traz um exemplo muito representativo em relação a essa abordagem do território-terra como corpo - ou, como propomos, do território-corpo da terra, a partir de grupos indígenas venezuelanos.

Já na apresentação de seu trabalho o autor reivindica a recuperação do "nós" - o "espírito nóstrico", o "fazer comunidade" - do qual as comunidades originárias foram alienadas com o despojo capitalista-colonial: "o primeiro e mais contundente passo do estabelecimento da dominação colonial e da colonialidade é desintegrar o nós da sua originária condição territorial e da práxis de sua territorialidade". (QUINTERO WEIR, 2019:12) Para resgatá-lo é fundamental recuperar a memória de suas territorialidades comuns originárias. É nesse sentido 
que ele retoma, por exemplo, a "perspectiva de ver e viver o mundo" por parte dos indígenas wayuu, na região do lago Maracaibo, fronteira entre Venezuela e Colômbia.

Quintero começa por nos mostrar o dilema quando se trata de "traduzir" nossa noção de território em uma língua indígena como a dos wayuu. Ele prefere, assim, buscar no idioma indígena as formas próprias com que designam seu espaço. A expressão mais próxima de "território" para os wayuu seria "Wouma'in", o conjunto do espaço ocupado por seu povo e por cada um de seus clãs. Na verdade:

Wouma'in, como expressão do sentipensar wayuu, só se refere indiretamente à noção de território e, mais diretamente, à noção vital da terra como sujeito vivo capaz de parir a vida de tudo aquilo presente como sujeito vivo no mundo, incluindo a dos homens e mulheres wayuu. (QUINTERO WEIR, 2019:13, grifos do autor)

Isso porque o termo reúne "W", "nós", e "ou", indicativo ao mesmo tempo da posição em/sobre uma superfície e do ato de emergir ou brotar sobre ela que, completando o termo, seria "ma", a terra. Não se trata, portanto, da simples "possessão [livre] do mundo", mas de uma "possessão ontogênica", de ligação estreita com a terra de onde emergem ("ma'in", o "coração da terra"), de pertencimento a ela. A exemplo de vários outros povos originários de Abya Yala, trata-se de uma leitura espacial e/ou "territorial" a partir da ampla concepção de espaço de vida.

No caso colombiano também temos exemplos dessa íntima conjugação entre território, terra (ou natureza) e corpo (como síntese de "vida"). A visão do território como território de vida fica clara na própria forma com que os indígenas colombianos miranha (também presentes na Amazônia brasileira) concebem o "manejo" frente àquela proposta por entidades governamentais. Segundo Echeverri (2004), eles advogam uma "consulta à natureza" onde os seres naturais também são concebidos como possuindo territórios. Esse caráter "consultivo e negociado" da política de manejo revela que "o território é um espaço de vida humana que se expande em negociação com outros espaços [naturais e sociais] a partir de um Centro", centro este que é o núcleo da vida humana. Trata-se de um nítido contraste com "a noção territorial desde a ciência da conservação", que "está centrada na vida silvestre, e a ação humana consiste em delimitar e demarcar áreas para garantir a reprodução dessa vida silvestre". (ECHEVERRI, 2004:271)

Não se trata, entretanto, na leitura do autor, de sobrevalorizarmos a questão dos distintos sentidos com que a palavra "território" é acionada nas duas concepções, mas de reconhecer que "ao estarem situadas em perspectivas diferentes, não têm como fazer referência aos mesmos objetos". 0 problema é também espacial no sentido da mudança de perspectiva em cada contexto vivido. E mais uma vez, também, o que está em jogo, em primeiro lugar, é o fortalecimento de boas relações sociais "que permitam o crescimento e a reprodução dos corpos". (ECHEVERRI, 2004:275)

Os indígenas almejam uma relação social que "permita a ambos [brancos e indígenas] reproduzirem-se em seus respectivos corpos: os indígenas reproduzindo suas famílias, suas chagras [áreas de cultivo], suas malocas e adquirindo bens e substâncias dos brancos que também necessitam para suas vidas". Echeverri conclui que "mais que diálogo intercultural para entender o território (como natureza), o que se necessita são boas relações sociais para construir o território como corpo." (ECHEVERRI, 2004:275) E não apenas como corpo "antropomórfico", deve-se acrescentar, pois a consideração dos territórios de outros seres vivos, como os animais, é fundamental. Deve-se então falar na interação entre múltiplos territórios(-corpo) de vida.

De modo análogo aos wayuu, outro povo aruaque, os añuu, da região do golfo e do lago Maracaibo, utilizam o termo "Wou'ree" para definir sua "ontogênese", agora enfatizando o espaço aquático (rios, lago e mar) em que se situam e agregando uma dimensão temporal. Assim, através da expressão designam "todo aquele lugar de água onde alguma das suas comunidades construiu vida e, portanto, tal lugar forma parte de seu território nas águas", devendo ser traduzida como "daqui emergimos, aqui estaremos". (QUINTERO WEIR, 2019:16) Observase aí que a relação com a terra na conformação territorial depende dos elementos "naturais" nos quais cada grupo cultural está inserido e com os quais mais intimamente se relacionam. Assim, como veremos a seguir, há quem proponha falar, por exemplo, de "água-território".

Muitas lutas que se pode denominar de ontológicoterritoriais estão focadas em uma ou mais dimensões da terra-território, dependendo também da constituição específica de cada grupo e das lutas que se desdobram no interior de seu "ambiente natural": em alguns casos se dão mais em função do acesso à água, em outros à terra para cultivar, em outros, ainda, da preservação das matas e seus recursos ... Incorporada a todas elas, contudo, é colocada em primeiro plano a questão da vida e da própria existência/sobrevivência, numa espécie de biopolítica às avessas ou "desde abajo".

No caso da água, Panez (2018) chega a propor a concepção de "água-território" em função da importância do debate territorial no entendimento dos tantos conflitos pela água em curso na América Latina. 
0 autor reconhece que os debates sobre a questão da água geralmente não explicitam a dimensão territorial, relacional, aí envolvida, muitas vezes fetichizando o conceito ao sobrevalorizá-lo através de um tratamento isolado ou, ainda pior, visto cada vez mais por uma ótica mercantilizada, ignorando o uso comum ${ }^{17}$.

Tratar o binômio água-território significa tratar sua inseparabilidade ao mesmo tempo que se reconhece sua não equivalência. Pensar este vínculo, segundo o autor, significa compreender:

a) la vinculación cultura-naturaleza presente en los procesos de apropiación del agua; b) las relaciones de poder desplegadas "en" y "a través" del territorio [inclusive no interior dos próprios movimentos sociais]; c) las lógicas de organización espacial con la producción de escalas; $y$, finalmente, d) las diferentes territorialidades de los actores protagonistas de los conflictos en curso. (PANEZ, 2018:216)

Zaragocin (2018b), cujas contribuições já foram aqui destacadas no que tange à noção de corpo-território, também contribui para este debate. A partir de um olhar feminista, propõe uma "descolonialidade feminista hemisférica de espaços aquáticos" (p. 8). Nesses espaços, especificamente, ela analisa especialmente "la relación entre agua-territorio y cuerpo-territorio desde las implicaciones de muerte-cuerpo-territorio para mujeres racializadas" (p. 9), e agrega à proposta de Panez sobre a água-território a relação corpo-território. Isso "generaría el concepto de agua-cuerpo-territorio, donde el cuerpo como primer territorio, ontológicamente conectado con el agua, alcanzaría otra dimensión de territorialidad". (p. 14) Indo além, Zaragocin propõe pensar em uma decolonização particular aos espaços aquáticos, agregando à leitura feminista a nova geografia da raça desdobrada por Juliet Hooker, onde a "racialização do espaço aquático" deve ser entendida através de uma "decolonialidade hemisférica", pois ela se dá, como demonstra Hooker, de sul a norte, em todo o continente americano. Gênero e raça, a partir de um olhar decolonial "latino-americanao", tornam-se assim indissociáveis da nossa condição territorial.

Essa visão decolonial predominantemente ecofeminista e/ou indígena do território se expande, como vimos, do corpo individual ao corpo da própria terra - ou da terra vista como corpo. Numa posição ainda mais ampliada dessa leitura "corpórea" e vivida do

17Uma obra que o autor destaca, entretanto, focaliza o que se denomina "territórios hidro-sociais", definidos como: "O imaginário disputado e a materialização socioambiental de uma rede multi-escalar espacialmente vinculada na qual humanos, fluxos de água, relações ecológicas, infraestrutura hidráulica, meios financeiros, arranjos legal-administrativos e instituições e práticas culturais são definidas, alinhadas e mobilizadas interativamente através de sistemas de crença epistemológica, hierarquias políticas e discursos naturalizantes". (Boelens et al., 2016:2; tradução livre) território, da territorialidade e da territorialização, temos a abordagem mais abrangente, aquela que interpreta como território o próprio mundo vivido por determinado grupo ou cultura em seu conjunto - ou até mesmo, no extremo, o conjunto de mundos (o "pluriverso") que garante nossa existência no planeta. Com toda a polêmica envolvida nesta perspectiva, a própria Terra pode ser vista como um organismo vivo, como na famosa hipótese de Gaia - a deusa grega da Terra e mãe de todos os seres vivos - uma Terra-mátria na leitura de diversos povos originários.

Nas diversas concepções territoriais dos povos originários (wayuu, añuu, bari, maranha, mas também mapuche, quéchua, guarani ...) há uma clara vinculação entre território (às vezes substituído pelo termo espaço ou lugar) e mundo, território e (planeta) Terra, pois o território de cada grupo se confunde com a totalidade ou integralidade de seu mundo. Vale aqui reproduzir essa afırmação dos índios misak, do Cauca colombiano, em que o território é considerado "o elemento mais sensível" de suas vidas, "elemento dinâmico e articulador" de sua cultura:

\footnotetext{
Los misak retomamos la lucha y venimos reconstruyendo la parte territorial y es el elemento más sensible de nuestra vida, en él se articulan todos los procesos culturales, ambientales, económicos y espirituales; es el elemento dinámico y articulador de los procesos vitales de nuestra cultura (Tunubalá e Muelas, 2008:16, apud QUIJANO VALENCIA, 2013:122)
}

Há aí um forte vínculo entre espaços funcionais à sobrevivência física, com os "recursos necessários" e locais carregados de simbolismo, sacralizados, fundamentais para suas noções de pertencimento. 0 indígena Ailton Krenak, do grupo Krenak, um grande líder indígena brasileiro, utiliza a noção de lugar, ao invés de território, para falar dessa ideia de pertencimento:

Pertencer a um lugar é fazer parte dele, é ser a extensão da paisagem, do rio, da montanha. É ter seus elementos de cultura, história e tradição nesse lugar. Ou seja, em vez de você imprimir um sentido ao lugar, o lugar imprime um sentido à sua existência ${ }^{18}$.

Essa afirmação é importante porque nos lembra que, analiticamente, entre os geógrafos, há uma tradição (notadamente de fundamentação fenomenológica) de tratar o termo lugar para enfatizar justamente as dinâmicas espaciais de construção identitária e de pertencimento. A leitura intelectual, entretanto, muitas vezes suprime ou deixa apenas implícito o valor desse

${ }^{18}$ Fonte: https://www.goethe.de/ins/br/pt/m/kul/fok/zgh/21806968.html (acessado em $1^{\circ}$ abr. 2020) 
sentido que o espaço (o lugar ou o território, dependendo da abordagem) "imprime" na nossa existência, como se fôssemos nós, apenas, os que teríamos o poder de "construir sentido" no (com o) lugar.

Uma concepção muito semelhante à desses outros grupos indígenas é aquela dos mapuche em sua luta de resistência e afirmação no sul do Chile. Para os mapuche, o território é definido como:

\begin{abstract}
...un espacio vital integral en el que estamos relacionados con los demás elementos del entorno natural y espiritual tanto de nuestros antiguos, como los del nguenmapu, lo que en el fondo son considerados vitales, ya que nos otorgan un linaje, una historia común. (...) El territorio posee una importancia fundamental ... se refiere también a una dimensión inmaterial, en la cual habitan diversas fuerzas espirituales que permiten la vida y la existencia de los mapuches. (LLAITUL E ARRATE, 2012:48)
\end{abstract}

Essa ideia recorrente do território como um "espaço vital", integrado/integrador ou "espaço de vida", onde habitam seres materiais e espirituais, muitas vezes se estende a todo o espaço partilhado por uma determinada cultura. Como afirma Quintero (2019), "para os povos indígenas cada um dos seus territórios se constitui como expressão do tamanho do mundo, assim se conforma como um universo: o universo da cultura" (p.18). A analogia com o corpo pode ser novamente aludida, agora na escala do "mundo", que pode se transformar no corpo feminino de "uma Mãe capaz de parir, prover e sustentar a vida das diversas comunidades" (Quintero, 2019:15). Aqui se trata também da Terra - planeta como um corpo, e o corpo da Terra como corpo feminino.

Reproduz-se assim uma concepção recorrente que, em muitas sociedades, enaltece a "maternidade" terrestre e concebe a Terra como um grande ser vivo que "nos pare" e "nos nutre", num amálgama indissolúvel entre homem e "natureza". Esse papel "maternal" da T/ terra é enaltecido desde, por exemplo, Mahimata, a "mãe terra" do Reg-Veda, um dos textos sagrados hindus, concebida como a "mãe de todos os deuses", numa clara ancestralidade matriarcal. Quintero nos lembra também a Abama (Mãe) Igiá (Terra) dos chibcha, mas a mais difundida e que inspirou diversas propostas políticas (inclusive de "direitos da natureza") é sem dúvida a Pacha Mama ou Terra Mãe dos povos andinos, intimamente alinhada com a proposta do Bem Viver (o sumak qamaña dos aimará e o sumak kawsay dos quéchua).

Assim, muitos grupos, especialmente nos altiplanos andinos, partilham de algum modo a mesma concepção de um território que não dissocia o homem da terra, tida como Pacha (universo, mundo) mama (mãe), onde todos os seres vivem em relação e onde a base física do terreno integra as relações sociais e em hipótese alguma pode ser reduzida à sua materialidade, pois tudo contém vida e, para o homem, adquire valor simbólico ${ }^{19}$.

Talvez pudéssemos afirmar que se passa do patriarcalismo de um "território pátria", tipicamente moderno-colonial (até pela sobrevalorização da concepção de território como território nacionalestatal) para o matriarcado de um "território mátria", decolonizador. Gutiérrez (2016), ao reelaborar a ideia de "tecido" social, se pergunta como redefinir a ideia de Pátria frente à "necessidade" de uma Mátria. Com essa questão, retorna-se ao debate sobre territorialidadeútero, agora o útero aparecendo como metáfora em nossa própria origem terrena:

¿Acaso tenemos que resignificar el concepto de Patria por el de Matría? (...) Matría en contraposición a Patria como lo sugirió Gonzáles y Gonzáles (1983;15), consiste en sustituir el "racional mundo del Padre" por el del mundo del terruño, el mundo pequeño y sentimental de la madre. Así la referencia a sociedades Otras apunta a la recuperación y construcción del comportamiento colectivo del cuidado de la vida. (GUTIERREZ, 2016:29, grifos da autora)

Ao identificar-se o "proceso de gestación del vivir contemporáneo y de aliento matriarcal" surge, igualmente, "el desafío de ser útero de relaciones no patriarcales". (GUTIERREZ, 2016:332). Para a autora, cabe assim:

\footnotetext{
Recuperar y defender organizadamente formas societales tradicionales de matriz matriarcal, y a la vez construir y recrear un arte que emerge del vínculo amoroso por la vida. La iniciativa, de este modo, impulsa un proyecto político de vida, resignificando territorios que están expresando la potencia de las resistencias de pueblos y colectividades que se filtran por las porosidades del sistema de dominación. ( $p$. 332-333)
}

Trata-se, portanto, de um espaço em que "tudo vive", onde tudo que configura este mundo está integrado (nunca são tomados como elementos individualizados) e se complementa numa relação de copertencimento ${ }^{20}$

\footnotetext{
${ }^{19}$ Esses componentes em plena interação também podem ser associados, metaforicamente, ao corpo humano, como revela o relato desta mulher indígena (identificada pelos autores como "Silvia"): "La Pachamama tiene vida porque en sus bosques se manifiesta energía, fuerza, coraje y plenitud, en sus ríos la circulación de la sangre, en sus suelos la carne viva, los lagos son los ojos que miran y lagrimean de alegría y de tristeza". (ANDRADE ZURITA et al., 2017:102)

${ }^{20}$ Segundo Esterman (1998), na filosofia andina "el principio de la complementariedad es perfectamente compatible con la negación de la substancialidad en el sentido de 'entes existentes en y por sí mismo' (...). Ningún 'ente' o acontecimiento particular es una entidad completa, sino que sufre - para hablar en términos occidentales - de una 'deficiencia ontológica', es decir: es en el
} fondo un 'no-ente', una 'nada'". (p. 126) 
onde todos podem ser vistos como "sujeitos" (QUINTERO, 2019:38) - e, porque não, com mais direito ainda, como "corpos". Desdobra-se uma espécie de "território de vida" que é, ao mesmo tempo, um "território-corpo do mundo", não só pela especificidade de cada grupo cultural mas também, numa leitura costumeira, por sua plena interação com a natureza. Desafiam-nos a rever a própria concepção de corporeidade através do ir e vir entre suas múltiplas escalas.

No fundo, se pensarmos bem, mesmo em sua concepção geograficamente mais difundida, a do território como espaço de exercício de (um) poder, como campo de forças (SOUZA, 1995), de controle da acessibilidade (SACK, 1986), de domínio (funcional) e apropriação (empoderamento simbólico) (HAESBAERT, 2004), os indígenas expandem a escala desse exercício de poder (imprescindível à sua sobrevivência) e nos colocam o desafio de "controlar" de modo amplo (funcional e simbólico) a própria Terra, "Pacha Mama", como território (ontologicamente) essencial à vida.

A perda desse controle, para os povos originários, ao contrário de um empresário capitalista, por exemplo, representa muito mais do que a perda de uma base de recursos - a ameaça a um território indígena significa a perda de todo um modo de vida, uma concepção de mundo, ligada de forma imanente à terra e a um conjunto de referenciais simbólicos aí envolvidos. De uma forma completamente distinta, enviesada, aos poucos os grandes capitalistas também vão se dando conta que seu "território" por excelência, e sobre o qual estão perdendo controle, é, em última (primeira) instância, o próprio planeta, seriamente limitado em termos de recursos e mesmo em área habitável (o ecúmeno), e onde muitas outras forças, não-humanas, (também) regem a construção do espaço.

Pode-se então afirmar que defender a vida e defender o território, território que se estende desde o nosso corpo até o "corpo da Terra", são ações inerentes uma à outra. Daí a proposta, desenvolvida especialmente por Arturo Escobar, de uma "ontologização do território": só se compreende o ser ao entender sua territorialidade. Escobar incorpora a ideia de ontologia política de Mario Blaser. Para este autor (LA CADENA E BLASER, 2018) a ontologia política se define em torno de alguns elementos centrais, entre eles a multiplicidade de conceitos como ferramentas para a produção de mundos e de acoplamento entre eles e a compreensão da política fomentada pela concepção de pluriverso. 0 debate ontológico deixa a estrita abstração filosófica, insere-se no mundo das práticas sociais e, segundo Escobar, "cria verdadeiros mundos".

Embora não seja possível aqui aprofundar esse debate, é importante reconhecer que essa perspectiva seria uma forma mais ampla e "radical" de conceber o território, reconhecendo essa dimensão ontológica como sua dimensão mais importante:

\begin{abstract}
... la perseverancia de las comunidades y movimientos de base étnico-territorial involucran resistencia, oposición, defensa y afirmación de los territorios, pero con frecuencia puede ser descrita de forma más radical como ontológica. De igual modo, aunque la ocupación de territorios colectivos usualmente involucra aspectos armados, económicos, territoriales (sic), tecnológicos, culturales y ecológicos, su dimensión más importante es la ontológica. (ESCOBAR, 2015:28)
\end{abstract}

Nesse raciocínio, os conflitos territoriais seriam, em última análise, pelo menos no caso dos povos originários, uma questão também de disputa entre distintas ontologias. Tal como na relação entre espaço (e território) no sentido absoluto (separável, "independente" um espaço do outro) e no sentido relativo/relacional (onde se privilegiam as conexões entre os espaços e, mais ainda, aquelas neles incorporadas), a "ontologia dualista" da modernidade hegemónica, que separa a cultura da natureza, o sujeito do objeto, faria frente a ontologias políticas, de caráter relacional. A partir do recurso a uma episteme ecológica ou ambiental, também defendida por Enrique Leff, Escobar propõe que essa luta em defesa dos territórios "repolitiza la ontologia, es decir, reanuda [retoma] la búsqueda de otras formas de ser-en-el-mundo". (ESCOBAR, 2018:91)

Os territórios, nessas ontologias relacionais, são "algo más que una base material para la reproducción de la comunidad humana", e esse "algo mais" só é captado pelo reconhecimento de outras ontologias, de outros mundos, que vão além do mundo humano, "cultural". Assim:

\footnotetext{
Cuando se está hablando de la montaña como ancestro o como entidad sintiente, se está referenciando una relación social, no una relación de sujeto a objeto. Cada relación social con nohumanos puede tener sus protocolos específicos, pero no son (o no solo) relaciones instrumentales y de uso. Así, el concepto de comunidad, en principio centrado en los humanos, se expande para incluir a no-humanos (...). Consecuentemente, el terreno de la política se abre a los no-humanos. (ESCOBAR, 2018:103-104)
}

Essas múltiplas composições de interrelações complexas entre humanos e não-humanos abre nossa compreensão da configuração de outros mundos, de ontologias múltiplas - de um "pluriverso" ou, em nossos próprios termos, de uma multi ou pluriterritorialidade. Mas isso já é questão para outros, amplos, horizontes de análise. 
Algumas considerações finais

A ênfase dada por muitos grupos sociais latinoamericanos, especialmente os povos originários e movimentos de mulheres - principalmente mulheres indígenas, ao corpo-terra-território como categoria da prática, é reveladora, antes de tudo, da importância do território de vida, aqui denominado território de r-existência, contra as tantas ameaças e violências que esses grupos vêm sistematicamente sofrendo. Uma concepção decolonial, complexa e não dualista, de "corpo" brota de uma noção de corporeidade em toda a sua multiplicidade (o que inclui não apenas a condição de gênero, raça e faixa etária, mas os distintos papéis de seus diferentes órgãos - como o útero, no caso das mulheres) e, como afirma Cruz Hernández na abertura deste texto, na conjugação entre corpo individual e corpo social ${ }^{21}$.

Trata-se de grupos cuja existência se deve a essa relação indissociável de seus corpos/afetos com os espaços de vivência cotidiana, rompendo, relacionalmente, com a visão dicotômica entre materialidade e espiritualidade, sensibilidade e consciência, natureza e sociedade e, obviamente, corpo e espírito, pois a concepção de corpo/corporeidade embutida nesses "territórios-corpo" é profundamente moldada, também, por um conteúdo simbólico ou, se preferirmos, espiritual.

$\mathrm{Na}$ verdade, falar em corpo-terra-território (nas diferentes combinações destes termos) é falar, como vimos, tanto da etno quanto da biodiversidade, conjugando-as. Assim, temos derivações de controle territorial dependendo do elemento mais importante a ser controlado - ao lado da mais genérica terraterritório podemos ter a água-território e, no caso da defesa das matas, a floresta-território ou, até mesmo, uma montanha-território, no caso da luta contra o grande extrativismo mineral.

Alguns poderão alegar que, por sua excessiva amplitude, estendendo-se da escala do corpo humano à escala mundial planetária, essas concepções de território perderiam muito de seu rigor analítico. De qualquer forma, entretanto, como foi visto através de vários exemplos concretos, não há como ignorar a força dessas concepções como categorias da prática e enquanto ferramentas de luta, especialmente no que tange aos movimentos feministas e/ou dos povos originários.

Podemos dizer que, em se tratando de território, o grande elo "práxico" entre prática, uso efetivo no

${ }^{21}$ Foucault (2002) dirá que nas tecnologias biopolíticas modernas não se trata do "corpo social", tal como reconhecido juridicamente, mas do "corpo múltiplo" a que ele denomina também "população". cotidiano, e análise, reflexão teórica, sempre se dará pela imbricação espaço-poder - ampliando-se a concepção de poder, como foi comentado, ao inserir claramente a sua dimensão simbólica (no "empoderamento identitário" decolonial de etnia e gênero, por ex.). Assim, se os povos originários propõem lutar pelo território, começando por seus próprios corpos (em especial no caso das mulheres) e estendendo-se até o conjunto de seus "mundos", é porque entendem que o que está em jogo, o que está sendo ameaçado em última instância é a própria vida - e não somente a deles, na medida em que partilham de uma concepção de "corpo", humano e planetário, comum.

Assim, se o território é construído na luta, no embate diante de uma ameaça - que, no extremo, é a ameaça à própria existência, frente à qual é preciso resistir - ele também é construído na luta por manter, por preservar a vida que se tem. É neste sentido que se pode falar na importância, hoje, dos territórios de cuidado, do cuidado com o território, tornado ainda mais evidente frente à pandemia de coronavírus. Defender é também zelar, cuidar daquele território sobre o qual nos consideramos responsáveis, em especial nosso corpo e sua extensão imediata, nossa casa, que constituem, juntos, nossa morada. Há, como afirma Bollnow (2008[1991]), um sentido expandido de encarnação do homem no corpo e na casa que "habitamos". Justamente quando mais parecíamos desprezar e nos apartar da corporeidade que, em sentido mais amplo é, também, espacialidade ela se evidencia com mais veemência. Definitivamente, a pandemia escancarou, estamos encarnados, incorporados ao mundo que, ao mesmo tempo, nos rodeia e nos constitui. 
Referências:

ANDRADE ZURITA, S. ; GARCIA OLIVA, M. e YUNGÁN, R.. 2017. La Pachamama: mujeres trabajando com o que tierra nos da. In: Lima, E. F. e Aurazo, C. (orgs.) Identidade e diversidade cultural na América Latina. Porto Alegre: Editora Fi.

BARNSLEY, J. 2006. El cuerpo como territorio de la rebeldía. Caracas: Unearte.

BOELENS, R. et al. 2016. Hydrosocial territories: a political ecology perspective. Water International n. 1, vol. 41, p. 1-14.

BOLLNOW, O. F. 2008 (1963) O homem e o espaço. Curitiba: Editora UFPR.

CABNAL, L. 2010. Acercamientos a la contrucción de la propuesta de pensamiento epistemológico de mujeres indígenas feministas comunitarias de Abya-Yala. Feminismos diversos: el feminismo comunitario. ACSUR, p. 1125.

CASTRO-GÓMEZ, S. e GROSFOGUEL, R. 2007. Prólogo. Giro decolonial, teoría crítica y pensamiento heterárquico. In: Castro-Gómez, S. e Grosfoguel, R. (orgs.) El giro decolonial. Reflexiones para una diversidad epistémica más allá del capitalismo global. Bogotá: Siglo del Hombre, Universidad Central, Instituto de Estudios Sociales Contemporáneos, Pontificia Universidad Javeriana, Instituto Pensar.

CRUZ, V. C. 2017. Geografia e pensamento descolonial: notas sobre um diálogo necessário para a renovação do pensamento crítico. In: Cruz, V. C. e Oliveira, D. A. (org.) Geografia e giro descolonial: experiências, ideias e e horizontes de renovação do pensamento crítico. Rio de Janeiro: Letra Capital.

CRUZ HERNÁNDEZ, D. T. 2017. Una mirada muy otra a los territorios-cuerpos femeninos. Solar, vol. 12, n. 1, p. 35-46.

DELEUZE, G. e GUATTARI, F. 1997 (1980) Mil Platõs: capitalismo e esquizofrenia. São Paulo: Editora 34.

ECHEVERRí, J. A. 2004. Territorio como cuerpo y territorio como naturaleza: diálogo intercultural? In: Surrallés, A. e García Hierro, P. (orgs.) Tierra adentro: territorio indígena y percepción del entorno. Copenhague: Grupo Internacional de Trabajo sobre Asuntos Indígenas.

ECHEVERRÍ, J. e BOTERO, R. 2002. Política territorial o territorializar la política: la Dirección Territorial Orinoquía Amazonía. In: Parques con la gente II: política de participación social en la conservación. Unidad Administrativa Especial del Sistema de Parques Naturales de Colombia. Bogotá: Ministerio del Medio Ambiente.

ELDEN, S. 2013. The birth of territory. Chicago: The University of Chicago Press.

ESCOBAR, A. 2018. Sentipensar con la tierra: nuevas lecturas sobre desarrollo, territorio y diferencia. Medellín: UNAULA.

2015. Territorios de diferencia: la ontología política de los "derechos al territorio". Cuadernos de Antropología Social n. 41.

ESTERMAN, J. 1998. Filosofía andina: estudio intercultural de la sabiduría autóctona andina. Quito: Abya Yala.

FOUCAULT, M. 2002 (1997) Em defesa da sociedade: curso no Collège de France (1975-1976). São Paulo: Martins Fontes.

1994. Dits et Écrits. Vol. III. Paris : Gallimard.

1984a (1975) Vigiar e Punir. Petrópolis: Vozes.

1984b (1984). História da Sexualidade II, O Uso dos Prazeres. Rio de Janeiro: Graal.

GUDYNAS, E. 2009. Diez tesis urgentes sobre el nuevo extractivismo. In: CAAP; CLAES. Extractivismo, política y sociedad. Quito: Centro Andino de Acción Popular; Centro Latino Americano de Ecología Social.

GUTIERREZ, D. I. 2016. Sociedades Otras : recuperación, reconfiguración y resignificación territorial en México. Aproximaciones a la expresión territorial zapatista en Chiapas (2000-2016). Tese de doutorado em Estudios Sociales Agrarios. Córdoba: Universidad Nacional de Córdoba.

HAESBAERT, R. 2014. Viver no Limite. Rio de Janeiro: Bertrand Brasil.

2004. O mito da desterritorialização: do "fım dos territórios" à multiterritorialidade. Rio de Janeiro: Bertrand Brasil. 
LA CADENA, M. e BLASER, M. 2018. A world of many worlds. Duke e Londres: Duke University Press.

LEFEBVRE, H. 1986 (1974) La production de l'espace. Paris: Anthropos.

LEPECKI, A. 2011. Coreopolítica e coreopolícia. Ilha v. 13, n. 1, p. 41-60.

LIMA, E. 2007. Do corpo ao espaço: contribuições da obra de Merleau-Poonty à análise geográfica. GEOgraphia v. 9, n. 18, p. $65-84$.

LIMA, I. 2020. A condição geopolítica dos corpos sensíveis. Paisagens Híbridas. Disponível em: https:// paisagenshibridas.eba.ufrj.br/2020/04/01/a-condicao-geopolitica-dos-corpos-sensiveis/ (acessado em 2 abr. 2020)

LINDÓN, A. 2012. Corporalidades, emociones y espacialidades: hacia un renovado betweeness. Revista Brasileira de Sociologia da Emoção v. 11, n. 33, p. 698-723.

LLAITUL, H. e ARRATE, J. 2012. Weichan: conversaciones con un weychafe en la prisión política. Santiago: Ceibo.

McDOWELL, L. 1999. Gender, identity and place : understanding feminist geographies. Minneapolis : University of Minnesota Press.

PANEZ, A. 2018. Agua-territorio en América Latina: contribuciones a partir del análisis de estudios sobre conflictos hídricos en Chile. Rupturas 8 (1), p. 201-225.

PEREIRA, E. 2017. Resistência descolonial: estratégias e táticas territoriais. Terra Livre v. 2, n. 43, p. 17-55.

PILE, S. 1996. The body and the city: psychoanalysis, space and subjectivity. Londres: Routledge.

PILE, S. e NAST, H. 1996. Places through the body. Londres e Nova York: Routledge.

PORTO-GONÇALVES, C. W. 2013 (2006) La reinvención de los territorios: la experiência latino-americana y caribeña. In: Porto-Gonçalves, C. W. Territorialidades y lucha por el territorio em América Latina. Lima: Unión Geográfica Internacional.

2009. Territorialidades y lucha por el territorio en América Latina: Geografía de los movimientos sociales en América Latina. Maracaibo: Instituto Venezolano de Investigaciones Científicas.

QUIJANO, A. 2010. Colonialidade do poder e classificação social. In: B.S. Santos e M. Meneses (eds.) Epistemologias do Sul. São Paulo: Cortez.

1992. Colonialidad del poder, etnocentrismo y América Latina. Indígena, 29, 11-21.

QUIJANO VALENCIA, O. 2013. Economía, ecosimías y perspectivas decoloniales. Elementos sobre visions y practices de diferencia económico/ cultural. In: Walsh, C. Pedagogías decoloniales: prácticas de resistir, (re)existir y (re)vivir. Vol. 1. Quito: Abya-Yala.

QUINTERO WEIR, J. A. 2019. Fazer comunidade: notas sobre território e territorialidade a partir do sentipensar indígena na bacia do Lago de Maracaibo, Venezuela. Porto Alegre: Deriva.

RAFFESTIN, C. 1993 (1980). Por uma Geografia do Poder. São Paulo: Ática.

ROSE, G. 1993. Feminism and Geography : the limits of geographical knowledge. Cambridge : Cambridge University Press.

SACK, R. 1997. Homo Geographicus: a framework for action, awareness and moral concern. Baltimore e Londres: Johns Hopkins University Press.

SERPA, A. 2013. Espacialidade do corpo e ativismos sociais na cidade contemporânea. Mercator vol. 12, n. 29, p. 2330.

SILVA, J. e ORNAT, M. 2016. Corpo como espaço: um desafio à imaginação geográfica. In: Pires, C.; Heidrich, A. e Costa, B. (orgs.) Plurilocalidade dos sujeitos: representações e ações no território. Porto Alegre: Compasso Lugar-Cultura. SIMONSEN, K. 2005. Bodies, sensations, space and time: the contributions from Henri Lefebvre. Geografiska Annaler 87B (1); 1-14.

SOUZA, M. 1995. O território, sobre espaço e poder, autonomia e desenvolvimento. In: Castro, I. et al. (orgs.) Geografia: conceitos e temas. Rio de Janeiro: Bertrand Brasil.

SVAMPA, M. 2019. Extractivism in LatinAmerica. Cambridge: Cambridge University Press.

VALENTINE, G. 2001. Social Geographies: space and Society. Harlow: Pearson Education.

VIVEIROS DE CASTRO, E. 2017 (entrevista) O que estamos vendo no planeta hoje é um combate de povos e não 
de classes, ou as classes estão voltando a se redefinir como povos. http://www.buala.org/pt/cara-a-cara/o-queestamos-vendo-no-planeta-hoje-e-um-combate-de-povos-e-nao-de-classes-ou-as-classes (acessado em 19 mai 2017)

2015. Metafísicas canibais: elementos para uma Antropologia pós-estrutural. São Paulo: Cosac Naify.

2013. A inconstância da alma selvagem e outros ensaios de Antropologia. São Paulo: Cosac Naify.

ZARAGOCIN, S. 2018a. La Geopolítica del útero: hacia una geopolítica feminista decolonial en espacios de muerte lenta. In: Cruz, D. e Bayon, M. (orgs.) Cuerpos, territorios y feminismos. Quito: Abya Yala y Estudios Ecologistas del Tercer Mundo.

2018b. Espacios acuaticos desde una descolonialidad hemisférica feminista. Mujer Sapiens, ano V, n. 10, p. 6-19. 